\title{
Neurological Complications of Endemic Skeletal Fluorosis, with Special Emphasis on Radiculo-Myelopathy
}

\author{
R. T. Haimanot, MD, FRCP(C) \\ Department of Internal Medicine, Faculty of Medicine, Addis Ababa University, PO \\ Box 1176, Addis Ababa, Ethiopia.
}

\begin{abstract}
Summary
The results of surveys carried out between 1976 and 1985 in the fluorosis-endemic area of the Ethiopian Rift Valley is summarised, with emphasis on the neurological complications resulting from the crippling osteofluorosis. The neurological manifestations in the forms of myelopathy with and without radiculopathy (respectively $72 \%$ and $28 \%$ ) occurred after exposure to high fluoride ( $>4 \mathrm{ppm}$ ) for longer than 10 years. These deficits were clearly found to be a consequence of fluoride deposition in bones, resulting in generalised sclerosis and osteophytosis, with reduction in the diameter of the intervertebral foramina and of the spinal canal. Advanced osteosclerosis commonly causes severe spastic quadriparesis in flexion, accompanied by distressing spasms and urinary incontinence. The dilemma of these medical problems in relation to the agro-industrial economic developments of the Ethiopian Rift Valley is discussed.
\end{abstract}

Key words: Skeletal fluorosis; Paraparesis; Radiculo-myelopathy.

Chronic fluorine intoxication has been documented to occur as a result of ingestion of large quantities of fluoride-rich waters over many years (World Health Organization, 1970), as well as in occupational exposure in those engaged in aluminium production, magnesium foundries, fluorspar processing, and superphosphate (Hodge and Smith, 1977).

Osteofluorosis and its complications, related to high-fluoride water consumption, have particularly gained attention in India (Siddiqui, 1955; Singh and Jolly, 1961; Jolly et al., 1968). Similar reports, but mainly on endemic dental fluorosis, have appeared also from the African continent, the majority from East African Rift Valley regions (Smith et al., 1953; Moller et al., 1970; Nair and Manji, 1982; Tekle-Haimanot et al., 1987).

In a previous study we reported on the epidemiology of endemic fluorosis in the Ethiopian Rift Valley (Tekle-Haimanot et al., 1987). This is a follow-up report on the neurological complications of skeletal fluorosis, predominantly in the forms of radiculo-myelopathies observed in the same region. 


\section{Materials, subjects and methods}

The Rift Valley, extending from north to south of the country, forms the volcanic breakline in the highland regions of Ethiopia. It extends south into Kenya and Tanzania, and north across the Red Sea and the Gulf of Akaba into the Dead Sea. The Ethiopian Rift Valley lies between 500 and $1800 \mathrm{~m}$ above sea level. It is hot and dry, with mean temperatures of 23 to $38^{\circ} \mathrm{C}$. The Rift Valley has a number of agro-industrial establishments, the most important being two sugar estates (Wonji-Shoa and Metahara), where 30000 people live.

Between 1976 and 1983, 530 workers were retired from Wonji-Shoa sugar estates at the age of 45 to 50 years because of inability to perform physically strenuous jobs. These workers were examined for evidence of skeletal fluorosis.

In August 1984, a medical board evaluated a further 300 workers of the WonjiShoa sugar estates who had presented with complaints of pains and aches, stiffness and progressive kyphosis suggestive of skeletal fluorosis. The medical board, of which the author was a member, examined these workers for evidence of skeletal fluorosis and neurological complications.

From March to December 1985, two clinical surveys were undertaken in 13 villages and towns to assess the extent and magnitude of endemic fluorosis in the Rift Valley. All persons with abnormal posture and deformities, confined to bed, were given general and detailed neurological examinations according to a pre-set protocol.

From the three clinical surveys, on all subjects with the diagnosis of skeletal fluorosis, the following data were recorded: sex, age, place of birth, length of residence in the study area, and the sources of drinking-water (piped water, stream, pond or irrigation canal), as well as subjective symptoms when relevant.

All identified subjects had radiological examinations of the spine and other bones. The radiological features were classified according to Roholm (1937): first stage-involvement of the spinal column and pelvis, and roughening and blurring of bony trabaculae; second stage-blurring of bone, and uneven contours; and third stage-bones showing the appearance of marble, with woolly configuration. The bones of the extremities show irregular periosteal thickening, and calcification of ligaments and muscular attachments.

Table I Prevalence of advanced skeletal fluorosis and neurological complications in the Ethiopian Rift Valley

\begin{tabular}{|c|c|c|c|c|c|c|}
\hline \multirow[t]{2}{*}{$\begin{array}{l}\text { Survey } \\
\text { area/year }\end{array}$} & \multirow{2}{*}{$\begin{array}{l}\text { Fluoride in } \\
\text { drinking water } \\
(\mathrm{ppm})\end{array}$} & \multirow[t]{2}{*}{$\begin{array}{l}\text { Symptomatic } \\
\text { persons }\end{array}$} & \multicolumn{2}{|c|}{$\begin{array}{c}\text { Clinical/radiological } \\
\text { fluorosis }\end{array}$} & \multicolumn{2}{|c|}{$\begin{array}{c}\text { Neurological } \\
\text { manifestations }\end{array}$} \\
\hline & & & No. & $(\%)$ & No. & $(\%)$ \\
\hline $\begin{array}{l}\text { Wonji/Shoa } \\
\text { 1976-1983 }\end{array}$ & $3 \cdot 7-17 \cdot 7$ & 530 & 244 & (46) & 3 & $(0 \cdot 6)$ \\
\hline $\begin{array}{l}\text { Wonji/Shoa } \\
1984\end{array}$ & $3 \cdot 7-17 \cdot 7$ & 300 & 195 & (65) & 39 & (13) \\
\hline $\begin{array}{l}\text { Alem Tena } \\
1984\end{array}$ & $9 \cdot 0$ & 30 & 15 & $(50)$ & 3 & $(10)$ \\
\hline $\begin{array}{l}\text { Sami Berta } \\
1984\end{array}$ & $9 \cdot 0$ & 18 & 10 & $(56)$ & 2 & (11) \\
\hline
\end{tabular}


After the surveys, those with neurological manifestations were followed up for a further 2 years. Five persons who developed overt neurological complications during the follow-up period were also included in this study.

Samples of drinking water from representative sites in the Rift Valley were analysed for fluoride content at the laboratory of the Wonji Sugar Estate Hospital, using ion analyser Orion Research Specific Ionometer. This has already been reported (Tekle-Haimanot et al., 1987).

\section{Results}

The water supplies in the Rift Valley came mainly from boreholes with a depth of from 10 to 100 metres; the majority were deep boreholes. Fluoride levels from these boreholes ranged from $1.0 \mathrm{mg} /$ litre to $36 \mathrm{mg} /$ litre (or parts per million, ppm). The sugar estates that had the highest population densities recorded high fluoride levels: Wonji-Shoa $3.7 \mathrm{ppm}$ to $17.7 \mathrm{ppm}$, and Metahara 2.4 to $7.0 \mathrm{ppm}$.

As shown in Table I, three areas (Wonji-Shoa, Alem Tena and Sami Berta) were identified as having occupants with clinically manifested skeletal fluorosis with neurological complications. The Wonji-Shoa sugar estates, the longest existing agro-industrial establishments in Ethiopia, recorded the highest number of cases of skeletal fluorosis and neurological complications. The prevalence showed a tendency to increase with the duration of residence in high fluoride areas.

Table II Neurological manifestations in 47 cases of advanced skeletal fluorosis

\begin{tabular}{|c|c|c|c|c|c|c|c|}
\hline \multirow[t]{2}{*}{ Neurological lesion } & \multicolumn{2}{|c|}{ Sex } & \multirow{2}{*}{$\begin{array}{l}\text { Bedridden } \\
\text { state }\end{array}$} & \multirow{2}{*}{$\begin{array}{l}\text { Incontinence } \\
\text { of urine }\end{array}$} & \multirow{2}{*}{$\begin{array}{c}\text { Patchy } \\
\text { sensory } \\
\text { deficit }\end{array}$} & \multirow[t]{2}{*}{ Decreased } & \multirow[t]{2}{*}{ Decreased } \\
\hline & Male & Female & & & & & \\
\hline Cervical radiculo-myelopathy & 15 & 1 & 2 & 1 & 6 & 12 & 5 \\
\hline Cervical myelopathy (pure) & 6 & - & 3 & 3 & - & 5 & 2 \\
\hline Cervical radiculopathy & 5 & 1 & - & - & 4 & - & 1 \\
\hline Cervicodorsal radiculo-myelopathy & 3 & & 1 & - & 1 & 1 & 1 \\
\hline Dorsal radiculo-myelopathy & 8 & 1 & 2 & 1 & 2 & 4 & 2 \\
\hline Dorsal myelopathy (pure) & 5 & & 2 & 2 & - & 4 & 1 \\
\hline Dorsal radiculopathy & 2 & & - & - & 1 & - & 1 \\
\hline Total and $(\%)$ & $44(94)$ & $3(6)$ & $10(21)$ & $7(15)$ & $14(30)$ & $26(53)$ & $13(28)$ \\
\hline
\end{tabular}

The neurological complications shown in Table II include predominantly radiculo-myelopathies $(80 \%)$; the majority of those involved the cervical region $(66 \%)$. 'Pure' myelopathies were found in $21 \%$. It is to be noted that, in osteofluorosis, it is often difficult to differentiate between radicular and myelopathic symptoms. In fluorotic radiculo-myelopathies generally, sensory symptoms are not very prominent.

The sensory symptoms tend to be patchy except when radicular pain in the upper limb is referred along a dermatome, or when cord compression is encountered. However, vibration sensation is reduced in about one third of those affected.

Spinal cord compression with thoracic sensory levels was found in 4 patients, two of whom underwent laminectomy. They had spastic paraparesis, sensory levels and severe painful abdominal muscle and leg spasms. Myelogram was difficult because of the difficulty of entering the subarachnoid space during lumbar puncture. The thickened bones and calcified ligaments made the laminectomies technically very difficult. The spinal canals in both cases were found to be 
narrowed by marked osteophytosis, with severe compression of the spinal cord. Following the laminectomy, however, there was appreciable relief from the painful spasms, and some improvement of the paraparesis. The amelioration lasted for 2 to 3 years. Those who developed neurological complications were persons from fluorosis-endemic areas who had consumed water from deep wells with fluoride levels higher than $4 \mathrm{ppm}$, for periods of more than 10 years. At Wonji, the first evidence of skeletal fluorosis was documented in the early 1970s, 20 years after the establishment of the sugar estate.

Varying degrees of loss of hearing to high frequencies were found in $13 \%$ of affected persons. This cochlear eight nerve dysfunction, associated with skeletal fluorosis, has also been observed by Siddiqui (1955). The pathogenesis is most probably related to sclerosis of auditory ossicles.

Skeletal fluorosis affected males (94\%) rather than females. The affected persons were those engaged in physically strenuous duties performed in hot environments, such as agricultural workers exposed to the sun in the fields, and factory workers such as those stationed at the sugar boilers, where the surrounding temperatures reach 45 to $48^{\circ} \mathrm{C}$. No women were engaged in similar duties.

Patients with skeletal fluorosis complicated by neurological deficits had varying periods for the development of their symptoms. However, in the majority, it was possible to register a uniform history of insidious onset with a very slow progression, except in 2 patients who developed cervical myelopathic signs after trivial falls. Of the patients, $21 \%$ ended in a bedridden state after various different periods of progression.

Decompressive laminectomies in osteofluorotic cord compression resulted in reasonable initial improvement, which unfortunately was short-lived. Both patients, over time, developed recurrence of symptoms and advanced paraparesis, as they continued to live in the same endemic areas, consuming the high fluoride water. In many people affected by skeletal fluorosis, we have seen a gradual improvement of symptoms, following relocation of domicile to areas where the water has a normal fluoride composition. We have also observed that over a period of 3 to 5 years some patients have had an arrest of the progression of the condition, and in some patients there has been improvement of the neurological symptoms in patients who have changed to and have strictly adhered to the consumption of defluoridated water in the sugar estates.

Different degrees of radiological changes were found in the patients studied. Those with neurological sequelae exhibited the most severe third stage of radiological features, with osteophytosis and marked spinal canal narrowing (Fig. 1).

Although most of the patients affected came from low socioeconomical groups, the nutritional status of the majority was satisfactory. Overt malnutrition was not recorded.

\section{Discussion}

The involvement of the nervous system in skeletal fluorosis was reported in India as early as 1937 (Shortt et al., 1937), but the detailed description of the neurological deficits and the resultant syndromes appeared in the 1950s and 1960s (Siddiqui, 1955; Singh and Jolly, 1961; Jolly et al., 1968). There have also been scattered 

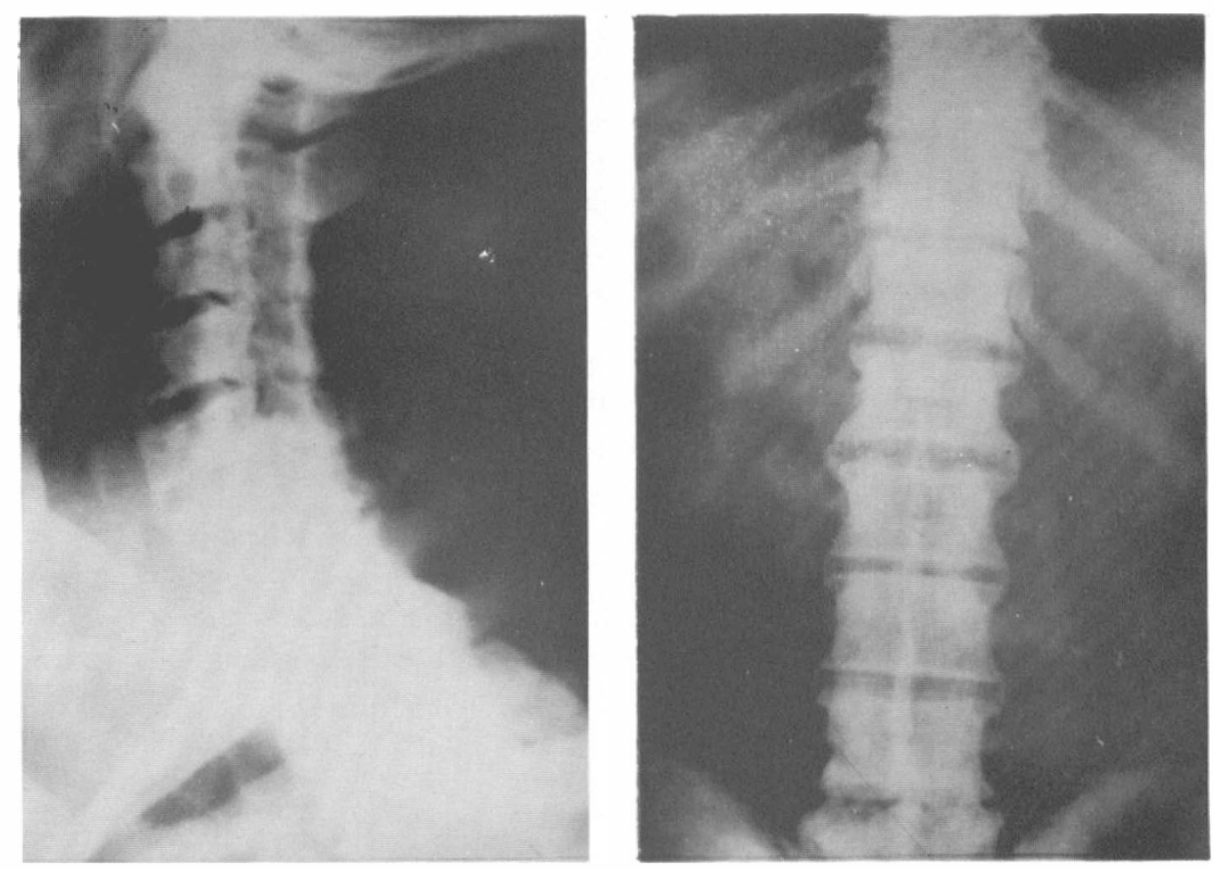

Figure 1 X-Rays of the cervical and lumbosacral spine of a patient with mild quariparesis, showing marked osteophytosis and narrowing of the cervical spinal canal.

reports from Britain (Webb-Peploe and Bradley, 1966) and from the United States (Goldman et al., 1971).

In Ethiopia, dental fluorosis was recognised as early as 1954 in the Rift Valley, particularly at the Wonji-Shoa sugar estates established in 1951. However, attention was drawn to skeletal fluorosis only in 1971, when the first spine X-rays were critically reviewed for evidence of skeletal involvement by abnormal deposition of fluoride. A case report of neurofluorotic myelopathy from the same area was published in 1974 (Lester, 1974). Subsequently, further similar cases were recognised.

With fluoride levels above $4 \mathrm{ppm}$, most of our patients developed neurological complications after 15 years of exposure. Corresponding observations have also been reported by Singh and Jolly (1970).

Associated factors, such as hot climate, sex, occupations, protein malnutrition and calcium deficiency have been incriminated as playing important roles in the development of skeletal fluorosis.

In our experience, high fluoride content in drinking water appears to play the most determinant role, as was observed by Reddy (1979). However, men doing manual labour in hot environments appear to be more susceptible to advanced osteosclerosis with neurological complications. Similar observations have been recorded by Siddiqui (1955) and Singh et al. (1961b).

The effect of high fluoride intake in children was not as obvious as in adults. Some cases of knock knees and bow legs, similar to those seen in India 
(Krissnamachari and Krishnaswamy, 1974) and in Tanzania (Grech, 1966), were seen in the early 1970s at Wonji-Shoa sugar estate.

However, the incidence of such disorders diminished gradually, probably as the result of the active programme of defluoridation of drinking water undertaken in the estates. Although radiologically evident skeletal fluorosis has been observed in children living in endemic areas (Krissnamachari and Krishnaswamy, 1974), it is now well documented that crippling fluorosis is not commonly encountered in children, but appears late in adulthood (Christie, 1980).

Before the onset of overt neurological symptoms, a person with skeletal fluorosis develops progressive bone pains and stiffness of the whole body. Squatting, particularly when defecating, becomes very troublesome. Standing up from a sitting position, and sitting up in bed, become increasingly difficult.

At the stage when neurological symptoms and signs become manifested, the affected persons have marked kyphosis, with stiffness and restriction of movement

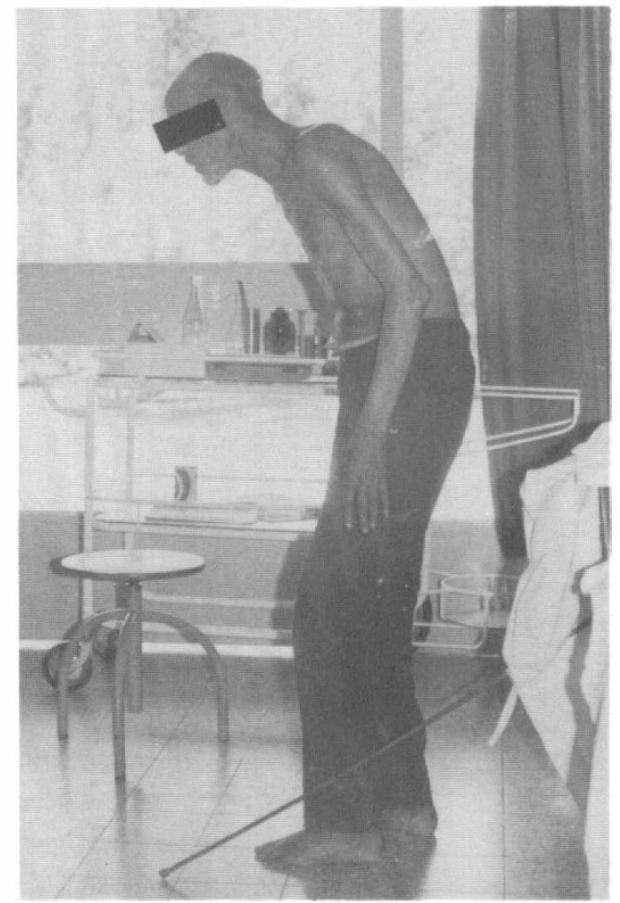

Figure 2 A 52-year-old factory-worker resident of the fluoride endemic Rift Valley for the last 31 years, with marked stiffness and fixed posture. He is unable to extend his neck and cannot squat. The whole body moves as a block during changing of position. He has weakness of the upper limbs and a spastic paraparesis.

of the whole body, which moves as a unit during postural changes (Fig. 2). Flexion deformity of the hip and knees and fixation of the chest wall are typically seen.

In the progressive cervical radiculo-myelopathy that develops insidiously, the common predominant neurological picture usually consists of marked wasting and atrophy of the small muscles of the hands, in addition to spastic paraparesis or quadriparesis, often in flexion. To a lesser extent, similar atrophies are seen in the 
lower limbs. In some patients, widespread fasciculation may be confused with motor neuron disease.

In advanced stages of neurofluorosis, the clinical picture is rather uniform, with complete incapacitation and the bedridden state of severe spastic paraparesis, or quadriparesis with incontinence of urine and flexor spasms. Hyperreflexia, with absent abdominal reflexes and extensor plantar responses with or without patellar and ankle clonus confirms long tract involvement.

The pathogenesis of the neurological sequelae of osteofluorosis is fairly straightforward, as was shown by the post-mortem study by Singh et al. (1961a) on a macerated skeleton, in which fluorotic changes resulted in considerable encroachment on the diameter of the intervertebral foramina and spinal canal.

These changes tend to be most marked in the cervical region. This explains the clinical similarity of neurofluorosis to cervical spondylosis. Two of our patients gave histories of minor traumas to the neck before the onset of their quadriparesis. This may well be accurate, as Symonds has described the importance of minor trauma causing cord injury in a situation of spinal canal narrowing by cervical spondylosis (Symonds, 1953).

Progressive idiopathic and predominantly motor myelopathy, as described elsewhere in tropical countries (Roman et al., 1985) is also encountered in Ethiopia (Jenik et al., 1981; Rynberg et al., 1988). This may, in some instances, be confused with the myelopathy of osteofluorosis, unless one is aware of the patient's area of origin and residence.

The prevention of skeletal fluorosis depends on obtaining alternative sources of low-fluoride drinking water; and includes defluoridation plants. Both of these are quite expensive for a poor country like Ethiopia. Although some defluoridation plants have been started in the sugar estates, more and more patients with osteofluorosis, with crippling neurological complications, are bound to be seen in the future.

\section{Acknowledgements}

The author thanks the Ethiopian Sugar Corporation for their assistance during the conduct of this study.

\section{References}

ChRISTIE DP 1980 The spectrum of radiographic bone changes in children with fluorosis. Radiology 136:85-90.

Goldman GM, Sievers ML, TEMPLIN DW 1971 Radiculomyopathy in a south-western Indian due to skeletal fluorosis. Ariz Med 28:672-677.

GRECH P 1966 Fluorosis in young persons. A further survey in northern Tanganyika, Tanzania. British fournal of Radiology 39:761-764.

Hodge HC, SMITH FA 1977 Occupational fluoride exposure. Fournal of Occupational Medicine 19:1239.

Jenik F, TEKLE-Haimanot R, Hamory BH 1981 Non-traumatic adhesive arachnoiditis as a cause of spinal cord syndrome. Investigation on 507 patients. Paraplegia 19:140-154.

Jolly SS, SINGH BM, MathuR DC 1968 Endemic fluorosis in Punjab (India). American fournal of Medicine 47:553-563.

KRISSNAMACHARI K, KRISHNASWAMY K 1974 An epidemiological study of the syndrome of genu valgum among residents of endemic areas for fluorosis in Andhra Pradeshi. Indian fournal of Medical Research 62:1415-1423.

LESTER F 1974 Fluoride myelopathy. Ethiopian Medical fournal 12:39-49. 
Moller IJ, Pindborg JJ, Gedalia I, Road-Petersen B 1970 The prevalence of dental fluorosis in the people of Uganda. Archives of Oral Biology 15:213-225.

NAIR KR, MANJI F 1982 Endemic fluorosis in deciduous dentation: a study of 1276 children in a typically high fluoride area (Kiambu) in Kenya. Odontostomatol Trop 4:177-184.

REDDY DR 1979 Skeletal fluorosis. In: VINKEN PJ, BRUYER GW (eds) Handbook of Clinical Neurology, Vol 36, Intoxication of the Nervous System, Part 1. North Holland Publishing Co, Amsterdam, pp 465-504.

RoноLм K 1937 Fluorine Intoxication. A Clinical-Hygienic Study with a Review of the Literature and Some Experimental Investigation. HK Lewis \& Co Ltd, London, p 124.

ROMAN GC, SPENCER PS, SCHOENBERG BS 1985 Tropical myelopathies: the hidden endemias. Neurology 35:1150-1170.

RYNBERG B, BlOMBERG J, KLASSE PJ 1988 Tropical paraparesis associated with human T-lymphotropic virus Type 1 in an East African naturalized in Sweden. British Medical fournal 295:1380-1381.

SHORTT HE, McRobert GR, BARNARD TW, NAYYAR ASM 1937 Endemic fluorosis in Madras Presidency. Indian Fournal of Medical Research 25:553-568.

SIDDIQUI AH 1955 Fluorosis in Nalgonda district, Hyderabad (Deccan). British Medical fournal 2:1408-1412.

SINGH A, JoLLY SS 1961 Endemic fluorosis, with particular reference to fluorotic radiculo-myelopathy. Quarterly fournal of Medicine 120:357-371.

SINGH A, Jolly SS 1970 Chronic toxic effects on the skeletal system. In Fluorides and Human Health. World Health Organization (Monograph Series No 59), Geneva, pp 237-249.

SINGH A, Jolly SS, BAUSAL BC 1961a Skeletal fluorosis and its neurological complications. Lancet 1:197-200.

Singh A, Jolly SS, Bausal BC, Mathur CC 1961 b Endemic fluorosis. Epidemiological, clinical and biochemical study of chronic fluorine intoxication in Punjab (India). Medicine 42:229-246.

SMITH DA, HARRIS HA, KIRK R 1953 Fluorosis in the Butan, Sudan. Fournal of Tropical Medicine and Hygiene 56:57-58.

SymondS C 1953 The interrelation of trauma and cervical spondylosis in compression of the cervical cord. Lancet 1:451-454.

Tekle-Haimanot, R, FeKadu A, Bushra B 1987 Endemic fluorosis in the Ethiopian Rift Valley. Tropical and Geographical Medicine 39:209-217.

WEBB-PEPLOE P, BRADLEY WG 1966 Endemic fluorosis with neurological complications in a Hampshire man. Fournal of Neurology, Neurosurgery and Psychiatry 29:577-582.

World Health ORganization 1970 Fluorides and Human Health. WHO (Monograph Series No 59), Geneva. 